\title{
Size-controllable synthesis of lithium niobate nanocrystals using modified Pechini polymeric precursor method
}

\author{
Cemile Yerlikaya $^{1} \cdot$ Najeeb Ullah $^{2} \cdot$ Ali Reza Kamali ${ }^{3}$ R. Vasant Kumar ${ }^{3}$
}

Received: 19 September 2015/Accepted: 3 February 2016/Published online: 23 February 2016

(C) The Author(s) 2016. This article is published with open access at Springerlink.com

\begin{abstract}
Nanopowders of lithium niobate $\left(\mathrm{LiNbO}_{3}, \mathrm{LN}\right)$ were synthesized by a water-based modified Pechini method, in which $\mathrm{Li}_{2} \mathrm{CO}_{3}$ and ammonium niobate (v) oxalate hydrate $\left(\mathrm{C}_{4} \mathrm{H}_{4} \mathrm{NNbO}_{9} \cdot x \mathrm{H}_{2} \mathrm{O}\right)$ are used as the $\mathrm{Li}$ and $\mathrm{Nb}$ source materials, respectively. The kinetics of formation of the intermediate gelatinous precursor was studied by thermal gravimetry and differential scanning calorimetry. The LN nanoparticles produced by calcining of the gel at various temperatures were characterized by $\mathrm{X}$-ray diffraction and scanning electron microscopy. The effect of the calcination temperature on the morphology and structure of LN nanoparticles produced is investigated. The particle and crystallite sizes of the $\mathrm{LN}$ prepared could be controlled in the range of $20-250 \mathrm{~nm}$ by changing the calcination temperature of the gelatinous precursor.
\end{abstract}

Keywords Lithium niobate Pechini method . Ammonium niobate (v) oxalate hydrate $\cdot$ Nanoparticle

Ali Reza Kamali

ark42@cam.ac.uk

1 Chemical Engineering Department, Istanbul Technical University, 34469 Maslak, Istanbul, Turkey

2 U.S.-Pakistan Center for Advanced Studies in Energy, University of Engineering and Technology Peshawar, Peshawar, Pakistan

3 Department of Material Science and Metallurgy, University of Cambridge, 27 Charles Babbage Road, Cambridge CB3 OFS, UK

\section{Introduction}

Lithium niobate (LN), a well-known ferroelectric material, has numerous applications in the electronic industry ranging from waveguides to nonvolatile memory elements [1]. Usually, $\mathrm{LN}$ powder is synthesized by conventional solid-state reaction using $\mathrm{Li}_{2} \mathrm{CO}_{3}$ and $\mathrm{Nb}_{2} \mathrm{O}_{5}$. This classical method of fabrication often results in compositional inhomogeneity and high agglomeration due to the loss of lithium at high calcination temperatures which can be as high as $1200{ }^{\circ} \mathrm{C}$ [2]. Recently, numerous alternate approaches have been described for the preparation of LN powder, including sol-gel [3], Pechini [4], hydrothermal [5, 6], combustion [7, 8], molten salt $[9,10]$, and mechanochemical [11] methods.

The Pechini technique is a wet chemical method and is based on the chelation of metallic ions using multifunctional carboxylic acids such as citric acid, in the presence of ethylene glycol. In this process, the polymerization of the complex is stimulated by heating the transparent solution and a uniform resin in which metal ions are homogeneously dispersed at molecular level, which ultimately results in the formation of $\mathrm{LN}[12,13]$ or other lithium metal oxide [14] nanoparticles with outstanding chemical uniformity. Furthermore, it is pertinent to mention that the lack of Li loss is ensured by the use of low-temperature methods resulting in the control of chemical composition of the product $[15,16]$. Other advantages of the Pechini method include the possibility to work in aqueous solutions in which starting materials can be solved easily. $\mathrm{Li}_{2} \mathrm{CO}_{3}$ is easily soluble in water and therefore commonly used as the Li source material for the preparation of $\mathrm{LN}$ powder in Pechini method.

Despite the above-stated benefits, there are still some difficulties with niobium source resources. Alkoxides of niobium which have been most widely used as the $\mathrm{Nb}$ source suffer from a drawback that they must be handled 
with great care since they are extremely sensitive to moisture and many also to oxygen and therefore should be handled in a highly dry inert atmosphere [2, 17]. Furthermore, alkoxides are very costly since their production involves numerous chemical processes. In comparison with alkoxides, chlorides are more cost-effective to be used as the starting material and also less sensitive to humidity, but often result in residual chlorine as contamination in the ultimate outcome [18]. Niobium oxide $\left(\mathrm{Nb}_{2} \mathrm{O}_{5}\right)$ is an inexpensive source compared to both alkoxides and chlorides, but the exceptionally high chemical stability of $\mathrm{Nb}_{2} \mathrm{O}_{5}$ confines its application in low-temperature reactions $[2,19]$. Therefore, the production of $\mathrm{LN}$ using $\mathrm{Nb}_{2} \mathrm{O}_{5}$ needs either hydrothermal method [5] or molten salt [10] processing condition. It is worth mentioning that hydrothermal preparation of $\mathrm{LN}$ using $\mathrm{Nb}_{2} \mathrm{O}_{5}$ requires high temperature $\left(240{ }^{\circ} \mathrm{C}\right)$ and extensive processing time $(72 \mathrm{~h})$ [6]. Alternatively, hydrous niobium oxide $\left(\mathrm{Nb}_{2} \mathrm{O}_{5} \cdot n \mathrm{H}_{2} \mathrm{O}\right)$, often called as niobic acid, is frequently used as highly reactive niobium precursor in the Pechini process and other sol-gel methods [14, 19]. Nevertheless, the preparation of hydrous niobium oxide is challenging as $\mathrm{Nb}_{2} \mathrm{O}_{5}$ should first be dissolved into HF [20]. Furthermore, the subsequent processing stages, including precipitation, are time consuming [21-24]. It should be noted that although niobic acid is the most widely used $\mathrm{Nb}$ source material in the production of alkali niobate, its compositional heterogeneity is highly possible since several compounds which promote the level of impurities are being used in the preparation process.

Niobium (v) ammonium oxo-tris (oxalate) monohydrate $\left[\left(\mathrm{NH}_{4}\right)_{3} \mathrm{NbO}\left(\mathrm{C}_{2} \mathrm{O}_{4}\right)_{3} \cdot \mathrm{H}_{2} \mathrm{O}\right.$ ] [25] or ammonium dihydrogen tris(oxalato) oxoniobate(v) trihydrate, $\mathrm{NH}_{4} \mathrm{H}_{2}\left[\mathrm{NbO}\left(\mathrm{C}_{2}\right.\right.$ $\left.\left.\mathrm{O}_{4}\right)_{3}\right] \cdot 3 \mathrm{H}_{2} \mathrm{O}[26,27]$, being soluble $\mathrm{Nb}$ salts, has been used for the production of alkali niobates by using hydrothermal synthesis [27], Pechini [28], thin-film preparation [29], evaporative [26], and combustion [30] methods. Nb oxalate, though soluble in water, has been used in different complex forms in order to enhance its gel formation capability [31, 32]. Asai et al. [33] used $\mathrm{NH}_{4} \mathrm{H}_{2}\left[\mathrm{NbO}\left(\mathrm{C}_{2} \mathrm{O}_{4}\right)_{3}\right] \cdot 3 \mathrm{H}_{2} \mathrm{O}$ for the preparation of $\mathrm{Nb}$ citrate complex and synthesized $\mathrm{SrBi}_{2}$ $\mathrm{Nb}_{2} \mathrm{O}_{9}$ by an aqueous solution route. Alternative $\mathrm{Nb}$ complex, niobium (v) peroxo-citrate, was synthesized from $\left[\left(\mathrm{NH}_{4}\right)_{3} \mathrm{NbO}\left(\mathrm{C}_{2} \mathrm{O}_{4}\right)_{3} \cdot \mathrm{H}_{2} \mathrm{O}\right]$ and used as precursor solution in the preparation of $\mathrm{K}_{0.5} \mathrm{Na}_{0.5} \mathrm{NbO}_{3}$ [25]. Recently, a novel and low-cost $\mathrm{Nb}$ source, ammonium niobate (v) oxalate hydrate $\left(\mathrm{C}_{4} \mathrm{H}_{4} \mathrm{NNbO}_{9} \cdot x \mathrm{H}_{2} \mathrm{O}\right)$, has been effectively used to make alkali niobates such as $\mathrm{Na}_{0.5} \mathrm{~K}_{0.5} \mathrm{NbO}_{3}$ [34], $\mathrm{Sr}_{0.6} \mathrm{Ba}_{0.4} \mathrm{Nb}_{2}$ $\mathrm{O}_{6}, \mathrm{LN}$, and $\mathrm{NaNbO}_{3}[35]$ by the Pechini technique.

The objective of this article is to present a simple and direct Pechini-type method which is capable of synthesizing high-purity crystalline LN nanoparticles with the desired size and composition. LN was synthesized from aqueous precursor solutions of ammonium niobate(v) oxalate hydrate and lithium carbonate in citric acid. The structural and microstructural properties of the synthesized powders at different calcination temperatures have been studied.

\section{Experimental}

The procedure employed for the preparation of $\mathrm{LN}$ is summarized in Fig. 1. The starting materials for the preparation of the precursor gel were lithium carbonate $\left(\mathrm{Li}_{2} \mathrm{CO}_{3}\right.$, $99.99 \%)$, ammonium niobate (v) oxalate hydrate $\left(\mathrm{C}_{4} \mathrm{H}_{4}\right.$ $\mathrm{NNbO}_{9} \cdot x \mathrm{H}_{2} \mathrm{O}(\mathrm{ANO}), 99.99 \%$, melting point $122{ }^{\circ} \mathrm{C}$ ), and ethylene glycol $\left(\mathrm{HOCH}_{2} \mathrm{CH}_{2} \mathrm{OH}, 99.8 \%\right)$ purchased from Sigma-Aldrich and citric acid $\left[\mathrm{HOC}(\mathrm{COOH})\left(\mathrm{CH}_{2} \mathrm{COOH}\right)_{2}\right.$, $99.5 \%$ ] from Fisher Scientific, UK. For this, the stoichiometric amount of lithium carbonate and ammonium niobate (v) oxalate hydrate were separately dissolved in citric acid solution. After stirring of both solutions for about $15 \mathrm{~min}$, ammonium niobate (v) oxalate solution was added to lithium carbonate solution and the resultant transparent mixture obtained was heated to $80{ }^{\circ} \mathrm{C}$. Then, ethylene glycol was added to the clear solution while maintaining the temperature at $80{ }^{\circ} \mathrm{C}$, in order to obtain the citric acid/ethylene glycol molar ratio of $2: 10$. The clear transparent $\mathrm{Li}-\mathrm{Nb}$ precursor solution obtained was kept at the same temperature for $6 \mathrm{~h}$ to produce a gelatinous precursor. It was found that the appropriate drying temperature depends on the dwell time. The precursor obtained was then calcined at different temperatures for $4 \mathrm{~h}$ in air to form nanoparticles of $\mathrm{LN}$.

The thermal decomposition behavior of the gelatinous precursor, including thermogravimetric (TG) and

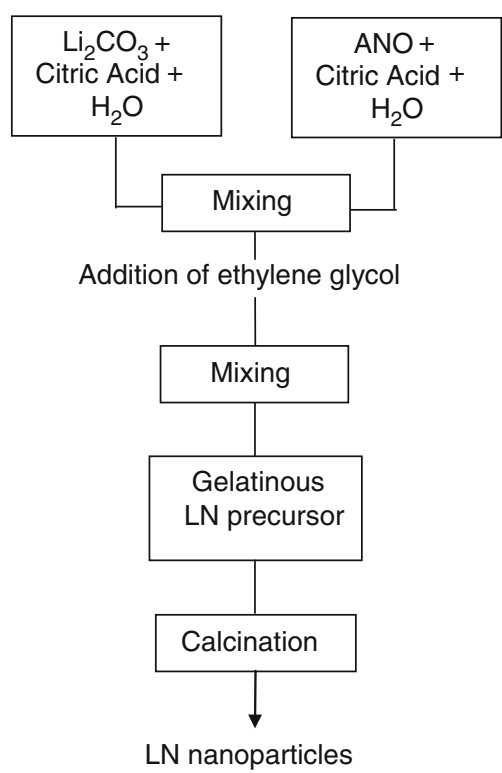

Fig. 1 Flowchart for the preparation of $\mathrm{LiNbO}_{3}$ by the modified Pechini method 
differential scanning calorimetry (DSC), was studied by a thermal analyzer model SDT-Q600, equipped with alumina crucibles. For this purpose, 20-mg gelatinous precursor was heated to $1000{ }^{\circ} \mathrm{C}$ at a heating rate of $20^{\circ} \mathrm{C} \mathrm{min}{ }^{-1}$ under a

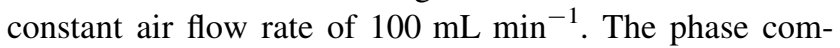
position of the heat-treated powders was identified by using a Bruker D8 X-ray diffractometer (XRD) with $\mathrm{Cu}-K_{\alpha}$ radiation, operated at $40 \mathrm{kV}$ and $40 \mathrm{~mA}$. The step size and dwell time were $0.03^{\circ} 2 \theta$ and $3 \mathrm{~s}$, respectively. The diffractograms were then analyzed using the X'Pert Highscore Plus program. Moreover, the crystallite size of the LN nanoparticles obtained was determined using the Scherrer's formula [36],

$C=0.9 \lambda / \beta \operatorname{Cos} \theta$

where $C$ is the crystal size, $\lambda$ is the wavelength of $\mathrm{Cu}-K_{\alpha}, \beta$ is the full width at half maximum (FWHM) intensity, and $\theta$ is Bragg' s angle. A JEOL 6340F field emission high-resolution scanning electron microscopy (SEM) was used for electron microscopy evaluations.

\section{Results and discussion}

The gelatinous LN precursor was prepared according to the procedure illustrated in Fig. 1. The thermal decomposition of the precursor obtained is shown in Fig. 2. A major mass loss of $70 \%$ is observed in the TG curve at a wide temperature range extending from 120 to $220{ }^{\circ} \mathrm{C}$. This event which is accompanied by an endothermic peak in the DSC curve at about $180{ }^{\circ} \mathrm{C}$ is attributed to the loss of free or bound water in the gelatinous structure $[37,38]$ as well as the elimination of excess ethylene glycol $[39,40]$.

The second major peak in the DSC curve of Fig. 2 is an exothermic peak at $560{ }^{\circ} \mathrm{C}$ which is accompanied by a mass loss of $17 \%$ at a temperature range of $400-625{ }^{\circ} \mathrm{C}$, as indicated in the TG curve. The exothermic peak can be attributed to the decomposition and hence elimination of the organic

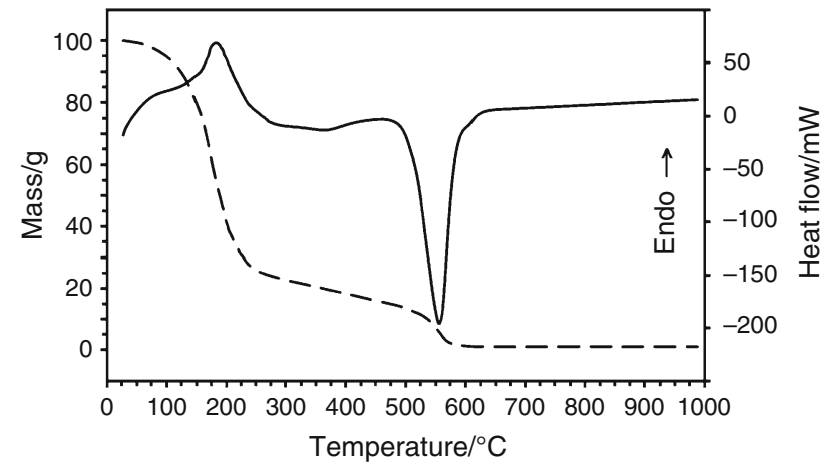

Fig. 2 TG and DSC curves of the LN precursor gel heated at the heating rate of $20{ }^{\circ} \mathrm{C} \mathrm{min}{ }^{-1}$ under a constant air flow rate of $100 \mathrm{~mL} \mathrm{~min}^{-1}$ materials. Cho et al. [41] suggested that the most polyester chains are broken during the annealing treatments at temperatures higher than $400{ }^{\circ} \mathrm{C}$ when the Pechini method is used. No further mass loss was observed at temperatures higher than $625{ }^{\circ} \mathrm{C}$ in TG curve, demonstrating the completion of the reactions leading to the formation of the final product.

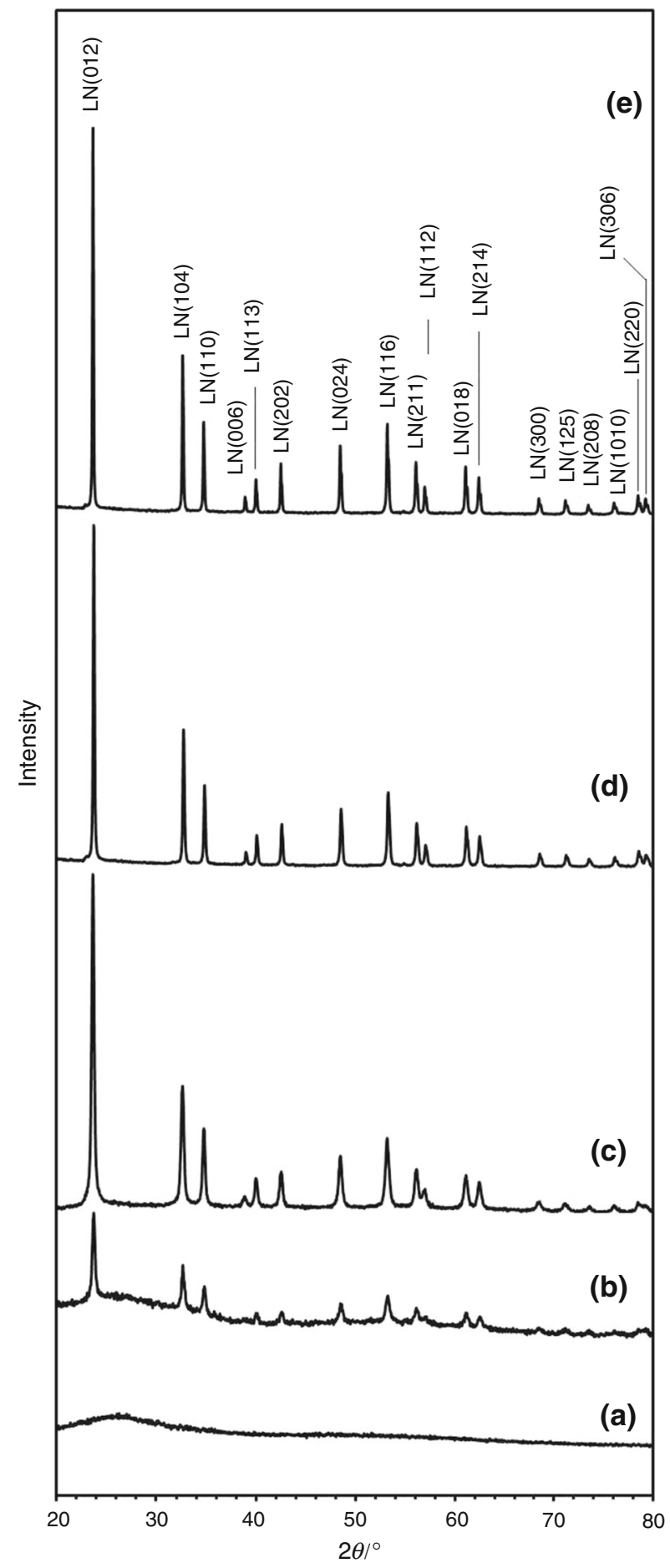

Fig. $3 \mathrm{X}$-ray diffraction patterns of the precursor calcined at $a 450$, $b 500, c 600, d 700$ and $e 800{ }^{\circ} \mathrm{C}$ in air for $2 \mathrm{~h}$ 
Fig. 4 SEM micrographs of LN nanoparticles obtained by calcination of the precursor at a $500{ }^{\circ} \mathrm{C}$, b $600{ }^{\circ} \mathrm{C}$, c $700{ }^{\circ} \mathrm{C}$ and $\mathbf{d} 800{ }^{\circ} \mathrm{C}$ in air for $2 \mathrm{~h}$
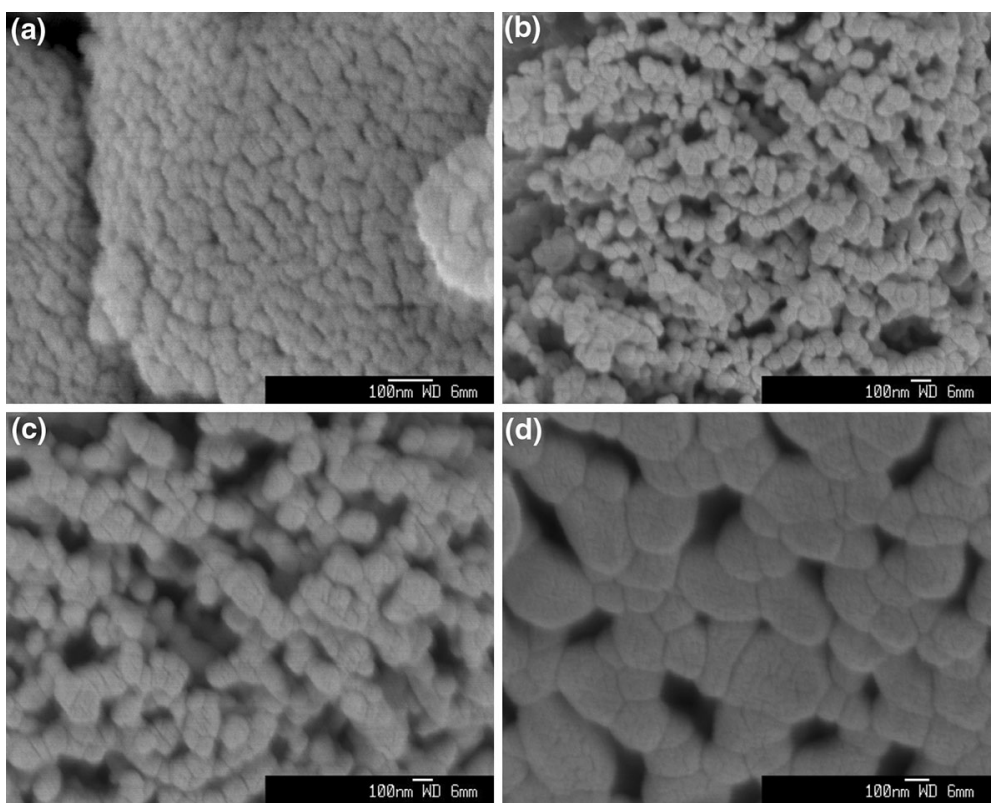

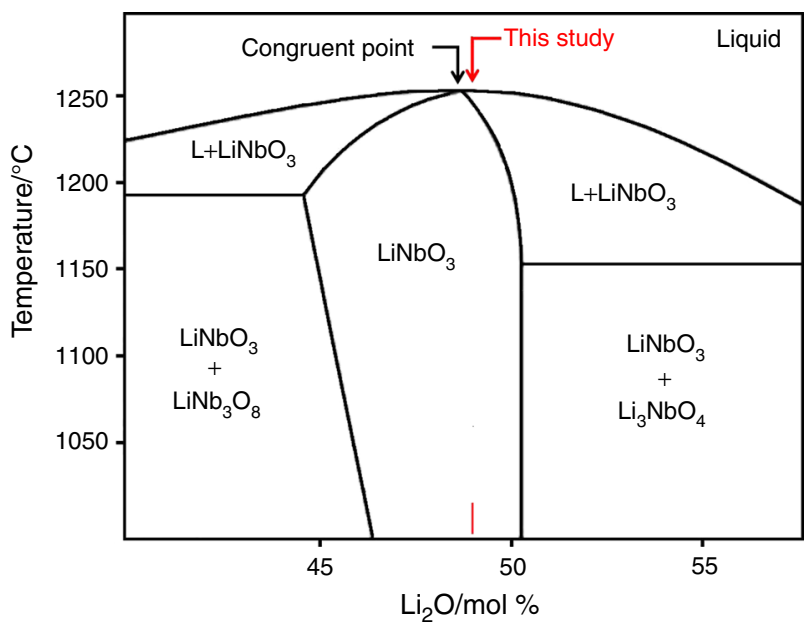

Fig. 5 Selected part of the $\mathrm{Nb}_{2} \mathrm{O}_{5}-\mathrm{Li}_{2} \mathrm{O}$ phase diagram, adapted from the widely accepted phase diagram drawn first by Svaasand [42]. The estimated chemical composition of the LN produced in this study (by calcination of the precursor at $800{ }^{\circ} \mathrm{C}$ ) is indicated by red in the figure. (Color figure online)

The LN precursor gel was calcined in air at different temperatures from 450 to $800{ }^{\circ} \mathrm{C}$, and the $\mathrm{LiNbO}_{3}$ powders formed were subjected to structural and microstructural evolution analysis. Figure 3 shows XRD patterns of the products formed by the calcination of the precursor gel at different temperatures. As it can be seen from Fig. 3a, the powder calcined at $450{ }^{\circ} \mathrm{C}$ is amorphous in structure, characterized by a single broad X-ray peak. Partial crystallization of $\mathrm{Li}-\mathrm{Nb}$ precursor gel has occurred during the annealing at $500{ }^{\circ} \mathrm{C}$ as confirmed by Fig. 3b. However, a reaction temperature above $600{ }^{\circ} \mathrm{C}$ was necessary for the synthesis of

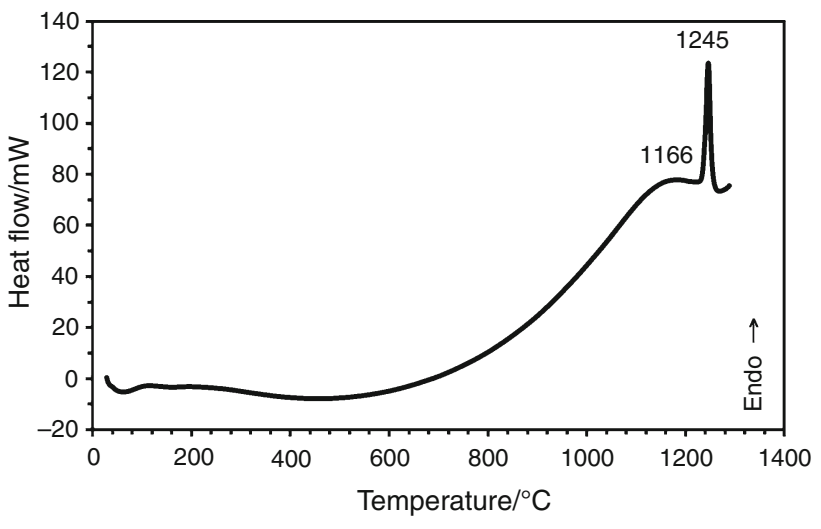

Fig. 6 DSC curve of the LN prepared by calcination of the precursor at $800{ }^{\circ} \mathrm{C}$. The measurement was conducted at the heating rate of $2{ }^{\circ} \mathrm{C} \min ^{-1}$ under a constant Ar flow rate of $100 \mathrm{~mL} \mathrm{~min}^{-1}$

well-crystallized LN powder (Fig. 3c-e) which is consistent with the thermal analysis results obtained. All the diffraction peaks observed in Fig. 3 are assigned to crystalline $\mathrm{LiNbO}_{3}$ without any indication of other crystalline phases such as $\mathrm{Li}_{3} \mathrm{NbO}_{4}$ [7] or $\mathrm{LiNb}_{3} \mathrm{O}_{8}$ [10] at the calcination temperatures higher than $600{ }^{\circ} \mathrm{C}$, demonstrating the preparation of pure $\mathrm{LN}$.

It can be seen from Fig. 3 that the intensity of LN peaks increases with increasing the calcination temperature, while the diffraction peaks become sharper and narrower, resulting in a decrease in the values of FWHM and hence the increase in the mean crystallite size values. The mean crystallite size of $\mathrm{LN}$ crystals formed at $500{ }^{\circ} \mathrm{C}$ was determined [using Eq. (2)] to be $20 \mathrm{~nm}$, which is smaller than those obtained by Popa et al. [4] who synthesized LN powders with a mean crystallite size of $40-60 \mathrm{~nm}$ using 
$\mathrm{Nb}$-ammonium complex $\left(\mathrm{NH}_{4}\left[\mathrm{NbO}\left(\mathrm{C}_{2} \mathrm{O}_{4}\right)_{3} \mathrm{H}_{2}\right] \cdot 3 \mathrm{H}_{2} \mathrm{O}\right)$ via the Pechini method. The mean crystallite size of the $\mathrm{LN}$ powders obtained at 600,700 , and $800{ }^{\circ} \mathrm{C}$ was determined to be 70,120 , and $230 \mathrm{~nm}$, respectively.

The morphology of the LN powders synthesized at different temperatures is shown in Fig. 4. The SEM micrograph of the sample prepared at $500{ }^{\circ} \mathrm{C}$ reveals the agglomerates of nanoparticles of about $20 \mathrm{~nm}$ in size. It can be clearly seen that the size of the LN nanoparticles increases with increasing the calcination temperature. The LN nanoparticles synthesized at 600,700 , and $800{ }^{\circ} \mathrm{C}$ can be found to have a mean particle size of about 80,100 , and $250 \mathrm{~nm}$, respectively. SEM micrographs presented in Fig. 4 are in excellent agreement with the XRD analysis results.

It is worth mentioning that $\mathrm{LiNO}_{3}$ rhombohedral crystal structure can exist in a range of chemical compositions around the stoichiometric composition consisting equal mole fraction of $\mathrm{Li}_{2} \mathrm{O}$ and $\mathrm{Nb}_{2} \mathrm{O}_{5}$, according to the phase diagram shown in Fig. 5.

The $\mathrm{Li}_{2} \mathrm{O}$ content of $\mathrm{LN}$ can be calculated from the following equation [43].

$C_{\mathrm{Li}}=19.149+2.557 \times 10^{-2} T_{\mathrm{C}}$

where $C_{\mathrm{Li}}$ is the crystal composition in $\mathrm{mol} \% \mathrm{Li}_{2} \mathrm{O}$ and $T_{\mathrm{C}}$ is the Curie temperature. The DSC curve of LN nanocrystals obtained by the calcination of the precursor at $800{ }^{\circ} \mathrm{C}$ is shown in Fig. 6, according to which the Curie temperature and the melting point of the product can be identified to be 1164 and $1245^{\circ} \mathrm{C}$, respectively. Based on the Curie temperature measured, the $\mathrm{Li}_{2} \mathrm{O}$ content of the LN nanocrystals prepared can be calculated to be $48.9 \mathrm{~mol} \%$. The estimated position of the $\mathrm{LN}$ produced is shown in red in Fig. 5. As it can be seen, the melting point and the chemical composition of the product are in a reasonable agreement with the phase diagram.

From the results obtained, it can be concluded that the modified Pechini polymeric precursor method discussed in this paper can provide control over the chemical composition and morphology of the product, enabling one to prepare pure $\mathrm{LiNbO}_{3}$ phase with desired particle sizes. This method offers a significant benefit over the conventionally used solid-state method which is based on the prolonged heating of $\mathrm{Nb}_{2} \mathrm{O}_{5}$ and $\mathrm{Li}_{2} \mathrm{CO}_{3}$, leading to the loss of stoichiometry by $\mathrm{Li}_{2} \mathrm{O}$ evaporation and thus the formation of undesired compounds such as $\mathrm{Li}_{3} \mathrm{NbO}_{4}$ and $\mathrm{LiNb}_{3} \mathrm{O}_{8}$ [44].

It should be mentioned that molten salt methods can efficiently produce LN [10] and other functional oxides $[45,46]$. In these methods, however, the control of particle sizes is usually difficult due to the high diffusion coefficients of the involved species. In the method discussed in this paper, a range of particle sizes from 20 to $250 \mathrm{~nm}$ could be achieve by calcining the precursor over a wide temperature range of $500-800{ }^{\circ} \mathrm{C}$, demonstrating the high capability of this method for controlling the particle sizes.

\section{Conclusions}

A modified Pechini route for the preparation of $\mathrm{LiNbO}_{3}$ nanoparticles was introduced. This method uses lithium carbonate and ammonium niobate (v) oxalate hydrate as the $\mathrm{Li}$ and $\mathrm{Nb}$ source materials, respectively, and provides an excellent control over size uniformity and chemical composition. It was found that the calcination of the gel precursor at $500{ }^{\circ} \mathrm{C}$ leads to the formation of $\mathrm{LN}$ nanoparticles of $20 \mathrm{~nm}$ in diameter. Increasing the calcination temperature leads to the increase in both the particle and crystallite sizes to about $250 \mathrm{~nm}$ at $800{ }^{\circ} \mathrm{C}$.

Open Access This article is distributed under the terms of the Creative Commons Attribution 4.0 International License (http://crea tivecommons.org/licenses/by/4.0/), which permits unrestricted use, distribution, and reproduction in any medium, provided you give appropriate credit to the original author(s) and the source, provide a link to the Creative Commons license, and indicate if changes were made.

\section{References}

1. Weis RS, Gaylord TK. Lithium niobate: summary of physical properties and crystal structure. Appl Phys A. 1985;37:191-203.

2. Liu M, Xue D, Luo C. Wet chemical synthesis of pure $\mathrm{LiNbO}_{3}$ powders from simple niobium oxide $\mathrm{Nb}_{2} \mathrm{O}_{5}$. J Alloys Compd. 2006;426:118-22.

3. Wang LH, Yuan DR, Yuan XL, Wang XQ, Yu FP. Synthesis and characterization of fine lithium niobate powders by sol-gel method. Cryst Res Technol. 2007;42:321-4.

4. Popa M, Kakihana M. Ultrafine niobate ceramic powders in the system $\mathrm{RE}_{\mathrm{x}} \mathrm{Li}_{1-\mathrm{x}} \mathrm{NbO}_{3}$ (RE: $\mathrm{La}, \mathrm{Pr}, \mathrm{Sm}, \mathrm{Er}$ ) synthesized by polymerizable complex method. Catal Today. 2003;78:519-27.

5. Yu J, Liu X. Hydrothermal synthesis and characterization of $\mathrm{LiNbO}_{3}$ crystal. Mater Lett. 2007;61:355-8.

6. Liu M, Xue D, Li K. Soft-chemistry synthesis of $\mathrm{LiNbO}_{3}$ crystallites. J Alloys Compd. 2008;449:28-31.

7. Kuo CL, Chen GJ, Chang YS, Fu JX, Chang YH, Hwang WS. Thermal behaviour of the nonstoichiometric lithium niobate powders synthesized via a combustion method. Ceram Int. 2012;38:3729-33.

8. Zhang X, Xue D, Liu M, Ratajczak H, Xua D. Microscopically structural studies of lithium niobate powders. J Mol Struct. 2005; 754:25-30

9. Afanasiev P. Synthesis of microcrystalline $\mathrm{LiNbO}_{3}$ in molten nitrate. Mater Lett. 1998;34:253-6.

10. Kamali AR, Fray DJ. Preparation of lithium niobate particles via reactive molten salt synthesis method. Ceram Int. 2014;40:1835-41.

11. Khalameida S, Sydorchuk V, Leboda R, Skubiszewska-Zięba J, Zazhigalov V. Preparation of nano-dispersed lithium niobate by mechanochemical route. J Therm Anal Calorim. 2014;115:579-86.

12. Pechini MP. Method of preparing lead and alkaline earth titanates and niobates and coating method using the same to form a capacitor. US Patent No. 3330697, 1967. 
13. Zhao JP, Liu XR, Qiang LS. Characteristics of the precursors and their thermal decomposition during the preparation of $\mathrm{LiNbO}_{3}$ thin films by the Pechini method. Thin Solid Films. 2006;515:1455-60.

14. Zhao JP, Quan MH, Zhang L. Preparation of potassium lithium niobate powders with low Li content via the Pechini method. Ceram Int. 2006;32:843-6.

15. Kullyakool S, Siriwong K, Noisong P, Danvirutai C. Studies of thermal decomposition kinetics and temperature dependence of thermodynamic functions of the new precursor $\mathrm{LiNiPO}_{4} \cdot 3 \mathrm{H}_{2} \mathrm{O}$ for the synthesis of olivine $\mathrm{LiNiPO}_{4}$. J Therm Anal Calorim. 2015;122:665-77.

16. Kokal I, Ramanujachary KV, Notten PHL, Hintzen HT. Sol-gel synthesis and lithium ion conduction properties of garnet-type $\mathrm{Li}_{6} \mathrm{BaLa}_{2} \mathrm{Ta}_{2} \mathrm{O}_{12}$. Mater Res Bull. 2012;47:1932-5.

17. Kakihana M, Szanics J, Tada M. Chemical design of highly water-soluble $\mathrm{Ti}, \mathrm{Nb}$ and precursors for multi-component oxides. Bull Korean Chem Soc. 1999;20:893-6.

18. Szanics J, Kakihana M. A novel tantalic acid-based polymerizable complex route of $\mathrm{LiTaO}_{3}$ using neither alkoxides nor chlorides of tantalum. Chem Mater. 1999;11:2760-3.

19. Wang X, Li W, Shi J. Synthesis and phase evolution of $\mathrm{LiNb}_{0.6-}$ $\mathrm{Ti}_{0.5} \mathrm{O}_{3}$ powder via a sol-gel method. Particuology. 2010;8:463-7.

20. Li Y, Zhao J, Wang $\mathrm{B}$. Low temperature preparation of nanocrystalline $\mathrm{Sr}_{0.5} \mathrm{Ba}_{0.5} \mathrm{Nb}_{2} \mathrm{O}_{6}$ powders using an aqueous organic gel route. Mater Res Bull. 2004;39:365-74.

21. Zhao J, Li Y, Wang B, Qiang L. Low temperature preparation of strontium barium niobate powders from metal carboxylate gels. Ceram Int. 2004;30:613-7.

22. Das RN, Pramanik P. Chemical synthesis of fine powder of lead magnesium niobate using niobium tartarate complex. Mater Lett. 2000;46:7-14.

23. Hou J, Vaish R, Qu Y, Krsmanovic D, Varma KBR, Kumar RV. Dielectric relaxation and electrical conductivity in $\mathrm{Bi}_{5} \mathrm{NbO}_{10}$ oxygen ion conductors prepared by a modified sol-gel process. J Power Sources. 2010;195:2613-8.

24. Zhang G, Hu Y, Ding X, Zhou J, Xie J. Wet chemical synthesis and photocatalytic activity of potassium niobate $\mathrm{K}_{6} \mathrm{Nb}_{10.8} \mathrm{O}_{30}$ powders. J Solid State Chem. 2008;181:2133-8.

25. Stavber G, Malic B, Kosec M. A road to environmentally friendly materials chemistry: low temperature synthesis of nanosized $\mathrm{K}_{0.5} \mathrm{Na}_{0.5} \mathrm{NbO}_{3}$ powders through peroxide intermediates in water. Green Chem. 2011;13:1303-10.

26. Lanfredi S, Dominguez SF, Rodrigues ACM. Preparation of $\mathrm{LiNbO}_{3}$ powder from the thermal decomposition of a precursor salt obtained by an evaporative method. J Mater Chem. 1995;5:1957-61.

27. Dias A, Ciminelli VST, Matinaga FM, Moreira RL. Raman scattering and X-ray diffraction investigations on hydrothermal barium magnesium niobate ceramics. J Eur Ceram Soc. 2001;21:2739-44.

28. Franco RCR, Camargo ER, Nobre MAL, Leite ER, Longo E, Varela JA. Dielectric properties of $\mathrm{Na}_{1-\mathrm{x}} \mathrm{Li}_{\mathrm{x}} \mathrm{NbO}_{3}$ ceramics from powders obtained by chemical synthesis. Ceram Int. 1999;25:455-60.

29. Zanetti SM, Vasconcelos JS, Vasconcelos NSLS, Leite ER, Longo E, Varela JA. $\mathrm{SrBi}_{2} \mathrm{Nb}_{2} \mathrm{O}_{9}$, thin films crystallized using a low power microwave oven. J Eur Ceram Soc. 2004;24:1597-602.
30. Zanetti SM, Santiago EI, Bulhoes LOS, Varela JA, Leite ER, Longo E. Preparation and characterization of nanosized $\mathrm{SrBi}_{2-}$ $\mathrm{Nb}_{2} \mathrm{O}_{9}$ powder by the combustion synthesis. Mater Lett. 2003;57:2812-6.

31. Narendar Y, Messing GL. Synthesis, decomposition and crystallization characteristics of peroxo-citrato-niobium: an aqueous niobium precursor. Chem Mater. 1997;9:580-7.

32. Nelis D, Van Werde K, Mondelares D, Vanhoyland G, Van Den Rul H, Van Bael MK, Mullens J, Van Poucke LC. Aqueous solution-gel synthesis of strontium bismuth niobate $\left(\mathrm{SrBi}_{2} \mathrm{Nb}_{2}\right.$ $\mathrm{O}_{9}$ ). J Sol-Gel Sci Technol. 2003;26:1125-9.

33. Asai T, Camargo ER, Kakihana M, Osada M. A novel aqueous solution route to the low-temperature synthesis of $\mathrm{SrBi}_{2} \mathrm{Nb}_{2} \mathrm{O}_{9}$ by use of water-soluble $\mathrm{Bi}$ and $\mathrm{Nb}$ complexes. J Alloys Compd. 2000;309:113-7.

34. Chowdhury A, O'Callaghan S, Skidmore TA, James C, Milne SJ. Nanopowders of $\mathrm{Na}_{0.5} \mathrm{~K}_{0.5} \mathrm{NbO}_{3}$ prepared by the Pechini method. J Am Ceram Soc. 2009;92:758-61.

35. Rodriguez EM, Kumar KU, Speghini A, Piccinelli F, Nodari L, Cannas C, Bettinelli M, Jaque D, Sole JG. Non-linear niobate nanocrystals for two-photon imaging. Opt Mater. 2011;33:258-66.

36. Langford JI, Wilson AJC. Scherrer after sixty years: a survey and some new results in the determination of crystallite size. J Appl Crystallogr. 1987;11:102-13.

37. Robert CL, Ansart F, Deloget C, Gaudon M, Rousset A. Powder synthesis of nanocrystalline $\mathrm{ZrO}_{2}-8 \% \quad \mathrm{Y}_{2} \mathrm{O}_{3}$ via a polymerization route. Mater Res Bull. 2001;36:2083-101.

38. Camargo ER, Longo E, Leite ER. Synthesis of ultra-fine columbite powder $\mathrm{MgNb}_{2} \mathrm{O}_{6}$ by the polymerized complex method. J Sol-Gel Sci Technol. 2000;17:111-21.

39. Tai LW, Lessing PA. Modified resin-intermediate processing of perovskite powders: part I. Optimization of polymeric precursors. J Mater Res. 1992;7:502-10.

40. Simões AZ, Gonzalez AHM, Cavalheiro AA, Zaghete MA, Stojanovic BD, Varela JA. Effect of magnesium on structure and properties of $\mathrm{LiNbO}_{3}$ prepared from polymeric precursors. Ceram Int. 2002;28:265-70.

41. Cho SG, Johnson PF, Condrate SRRA. Thermal decomposition of (Sr, Ti) organic precursors during the Pechini process. J Mater Sci. 1990;25:4738-44.

42. Svaasand LO, Eriksrud M, Grande AP, Mo F. Crystal growth and properties of $\mathrm{LiNb}_{3} \mathrm{O}_{8}$. J Cryst Growth. 1973;18:179-84.

43. Bordui PF, Norwood RG, Jundt DH, Fejer MM. Preparation and characterization of off-congruent lithium niobate crystals. J Appl Phys. 1992;71:875-9.

44. Kalinnikov VT, Gromov OG, Kunshina GB, Kuzmin AP, Lokshin EP, Ivanenko VI. Preparation of $\mathrm{LiTaO}_{3}, \mathrm{LiNbO}_{3}$, and $\mathrm{NaNbO}_{3}$ from peroxide solutions. Inorg Mater. 2004;40:411-4.

45. Kamali AR. Thermokinetic characterisation of tin(II) chloride. J Therm Anal Calorim. 2014;118:99-104.

46. Kamali AR, Fray DJ. Solid phase growth of tin oxide nanostructures. Mater Sci Eng B. 2012;177:819-25. 